\title{
Education and Diet in the Scientific Literature: A Study of the Productive, Structural, and Dynamic Development in Web of Science
}

\author{
Juan Antonio López Núñez ${ }^{\circledR}$, Jesús López-Belmonte ${ }^{\circledR}$, Antonio-José Moreno-Guerrero ${ }^{\circledR}$, \\ Magdalena Ramos Navas-Parejo *(D) and Francisco-Javier Hinojo-Lucena ${ }^{(D)}$ \\ Department of Didactics and School Organization, University of Granada, 18071 Granada, Spain; \\ juanlope@ugr.es (J.A.L.N.); jesuslopez@ugr.es (J.L.-B.); ajmoreno@ugr.es (A.-J.M.-G.); fhinojo@ugr.es (F.-J.H.-L.) \\ * Correspondence: magdalena@ugr.es
}

Received: 9 April 2020; Accepted: 11 June 2020; Published: 13 June 2020

\begin{abstract}
Nutrition-related education is necessary to protect and improve the health status of schoolchildren and to minimize the risk of future diseases. The objective of this research was to analyze the trajectory and transcendence of the concepts "education" and "diet" in the Web of Science literature. The methodology focused on bibliometry, analyzing both the performance and the structural and dynamic development of the concepts through a co-word analysis. A total of 1247 documents were analyzed, and the results show that scientific production experienced a turning point in 2009, in comparison to the level of production reported in previous years. The medium of papers and the language of English were the most common. In relation to the research topic, before 2014, scientific production focused on medical and disease-related aspects; however, since 2014, it has focused on disease prevention and feeding. It was therefore concluded that the theme "diet and education" has been researched for more than 20 years, although it is only in the last decade that it has become more relevant-particularly studies focusing on disease prevention and the type of food, specifically fruit, which is presented as the most outstanding issue for researchers in this field of knowledge.
\end{abstract}

Keywords: diet; education; bibliometric analysis; scientific production; scientific mapping; Web of Science

\section{Introduction}

Nutrition assumes a fundamental role to protect and promote an optimal state of health. Therefore, the follow-up of a diet in schoolchildren is important, as they are classified as a sensitive group in nutritional terms, meaning that they are at greater risk of malnutrition or poor diet for effective growth and development [1].

Diet is considered a key element for disease prevention, and thus, dietary recommendations from specialists should be followed in order to maintain and preserve a good state of health [2].

The World Health Organization states that many young people around the world have high rates of both overweight and obesity. This is generated as a result of not performing enough physical activity, in addition to not following a healthy diet [3]. Overweight and obesity are considered a serious public health problem, not only in developed countries, but also proliferating in developing countries [4]. This situation is causing a high mortality rate closely linked to a poor-quality diet [5].

In this sense, education plays a primary role in establishing good eating habits in people [6]. Specifically, dietary education can promote the adequate behavior of adolescents in the face of their 
inadequate diet [7]. In line with this, it has been observed that youths follow a diet with a high sugar content, which is detrimental to their health [8].

It has been proven that a four-week-long nutritional education program can help to improve dietary and nutritional patterns in adolescents [9]. Along these lines, other experts postulate that a diet education of only $20 \mathrm{~min}$ can cause a positive impact on young people's knowledge about nutrition [10].

These actions allow students to increase their knowledge about aspects related to nutrition and to change their attitude toward the intake of certain foods harmful to health [11]. Also, the continuity of these programs over time results in the consolidation and durability of a healthy lifestyle [12].

In primary education, it is important to apply training programs linked to the development of adequate dietary guidelines [13]. This is justified in the constant transformations that the human body undergoes in the first years of life [14] and in the personality development assumed by students at this stage [15], with the purpose of establishing healthy habits at a nutritional level that have a special impact on diet and that last for a lifetime [16]. The literature reflects the importance of carrying out training tasks in terms of nutrition and active lifestyles in order to raise awareness about good healthy habits and, thus, to prevent the proliferation of diseases at an early age [17].

Experts recommend a quality nutritional education for the development of adequate eating habits, especially in diabetic people [18] and those with heart problems or cardiovascular risk [19], in order to ensure a good state of health.

Traditional practices to boost eating habits among people have shown little importance in improving dietary patterns [20]. Therefore, nutritional training activities based on electronic resources such as mobile devices are increasing, proving to be effective for the implementation of a dietary follow-up [21]. In addition, innovative dietary education programs are being carried out through educational technology based on e-learning to reduce the barriers that some people may have to access a nutritional training program [22]. In addition, due to advances in technology, it is already possible to carry out dietary interventions using mobile applications [23], as well as health education through emerging technologies such as augmented reality [24].

Very few students and families have optimal knowledge regarding nutrition and dietetics, and those who do gained this knowledge from informal learning through self-study or through the recommendations of people they are close to in their environment [25]. In a survey of pre-university students, a need for these adolescents to receive nutritional information by specialists was observed, since the training they had already received was by nonexperts in the field of nutrition and dietetics [26]. A quality dietary education provided by qualified professionals can increase the indicators of obesity reduction and can facilitate the improvement of psychological factors [27].

Not only is it important to educate and instill in students good dietary guidelines, but also teachers of educational centers and staff in charge of school canteens must receive specific training related to the development of adequate diets where the supply of food that provides energy, fats, and saturated fatty acids is controlled [28].

The application of training programs related to active and healthy lifestyles, where the practice of physical activity is encouraged and the follow-up of a diet adjusted to the needs of each person, implies an improvement in biomedical parameters such as blood pressure, body mass index, fat reduction in body folds, and cholesterol [29]. In addition, the follow-up of dietary guidelines has been proven to have a positive impact on students' academic performance, obtaining better results than students with poor nutritional habits [30].

Marketing campaigns are already being used to encourage families to contribute to improving the diet offered to children, as well as to combat a sedentary lifestyle that currently affects the younger population [31]. Likewise, the demand for organic food is growing, but its consumption is not growing at the same rate, which is due to the value of the product [32]. A diet based on organic farming should be promoted [33]. However, all of this depends, to a large extent, on values of a social, emotional, and epistemic type that are related to the consumer's intentions [34]. 
Therefore, it is essential to follow dietary guidelines to promote an optimal state of health and to acquire all of the nutrients that the human body needs to function effectively in the different actions of daily life. In the same way, with correct feeding, the possibility of suffering diseases such as diabetes or hypertension is reduced. In this sense, schools assume an important role in both training and promoting healthy habits concerning food [35].

All of the above serves to present the state-of-the-issue rationale drawn from recent studies in the impact literature. This has led to the completion of this study, due to the gap found in science as a consequence of the absence of research that reflects, from a bibliometric perspective in particular, the evolution and current state of dietetic education. Likewise, it was necessary to carry out this study because it deals with a very sensitive topic at present, and to reveal to the scientific community all of its scientific projection from the first studies until today.

\section{Justification and Objectives}

The purpose of this research was to analyze, from a novel analytical approach, the path and transcendence of the concepts of "education" and "diet" (EDIE) in the impact literature collected from the Web of Science (WoS) database, in its entirety, with the intention of showing the Scientific Community the status of the issue of research development related to said terminology.

The novelty presented by this study, with respect to other works with the same intention [36], comes from the bibliometric analysis technique used. This technique not only focuses on the quantification of bibliometric indicators, but also on the dynamic and structural development of the delimited constructs, as reflected in other works [37,38]. Therefore, this research helps to reduce the gap found in the impact literature of this field of knowledge, by not finding any study of the same characteristics as the one presented in this manuscript.

The objectives formulated in this research are as follows: (a) to determine the performance and the production of scientific literature based on "diet" and "education"; (b) to determine the scientific evolution of the terms mentioned; (c) to establish the most outstanding topics in the field of study based on these terms; (d) to identify the most influential authors in the impact literature in relation to the concepts analyzed.

\section{Materials and Methods}

\subsection{Research Design}

This study followed a bibliometric research methodology, taking as reference other previous studies of high impact literature [39-44]. The reason why this research technique was used is reflected in the potentialities that Scientometrics reports have in aspects related to quantifying, evaluating, and estimating the scientific evolution of the field of knowledge in question [45].

This paper analyzes both the performance and the structural and dynamic development concerning "diet" and "education" through a co-word analysis [46]. This was done by taking the h-index and the volume of citations as the main indicators [47] for the preparation of scientific maps to analyze parameters such as performance and location and to determine conceptual subdomains, in order to establish thematic development [48]. In addition, other indicators such as the g-index, the hg-index, and the q2-index were taken into account to provide more information on the thematic metrics.

In this research, the Preferred Reporting Items for Systematic Reviews and Meta-Analyses (PRISMA-P) matrix analysis protocol was respected and various analytical tracking and documentary quantification techniques were used through the configuration of controlling variables at the literary level.

\subsection{Procedure and Data Analysis}

This investigation was carried out at different times. First, the database from which to extract the literary productions was selected. We chose WoS because it is a repository that contains a large 
volume of impact work. Second, the keywords to be entered into the WoS search tool were selected. For this, the information provided by the editors of the special issue titled "Nutrition Education in Medicine" of MDPI's Nutrients journal was analyzed. A consultation was then carried out in the Education Resources Information Center (ERIC) and United Nations Educational, Scientific and Cultural Organization (UNESCO) thesauri, with the intention of using the standardized terms found in the Scientific Community. Finally, the key words used were "diet" and "education." At first, a search was carried out by topic in WoS, of the keywords "diet" and "education," with the following search equation: [TOPIC] "diet" AND [TOPIC] "education." This type of search locates one of these words in either the title, the abstract, or the keywords; that is, if the word appears in any one of these three sections, it was included among the documents located. In this case, a total of 11,478 documents were obtained, of which the majority did not refer to the objectives set out in this investigation. These documents focused on other aspects of a medical nature. Due to this, another search was made, making a modification in the equation presented above: [TOPIC] "diet" AND [TITLE] "education." In this new search, attention was focused on the word "education" being in the title of the various documents, yielding a total of 1263 articles, obtaining, in this case, a scientific publication related to the objectives of this research.

The search process occurred in January 2020 to cover the entire literary volume of 2019 and previous years. The search result specified an analysis unit of 1263 documents. These documents were analyzed to rule out repeated or poorly indexed publications. In addition, various inclusion criteria were established (Table 1) in order to collect the most relevant and significant productions. Based on these criteria, the final sample was refined to 1247 scientific publications (Figure 1).

Table 1. Production indicators and inclusion criteria.

\begin{tabular}{cc}
\hline Indicators & Criteria \\
\hline Year of publication & $x \geq 1995$ \\
Language & $x \geq 10$ \\
Publication area & $x \geq 100$ \\
Type of documents & $x \geq 20$ \\
Organizations & $x \geq 20$ \\
Authors & $x \geq 6$ \\
Sources of origin & $x \geq 35$ \\
Countries & $x \geq 15$ \\
Citation & The four most cited documents \\
\hline
\end{tabular}

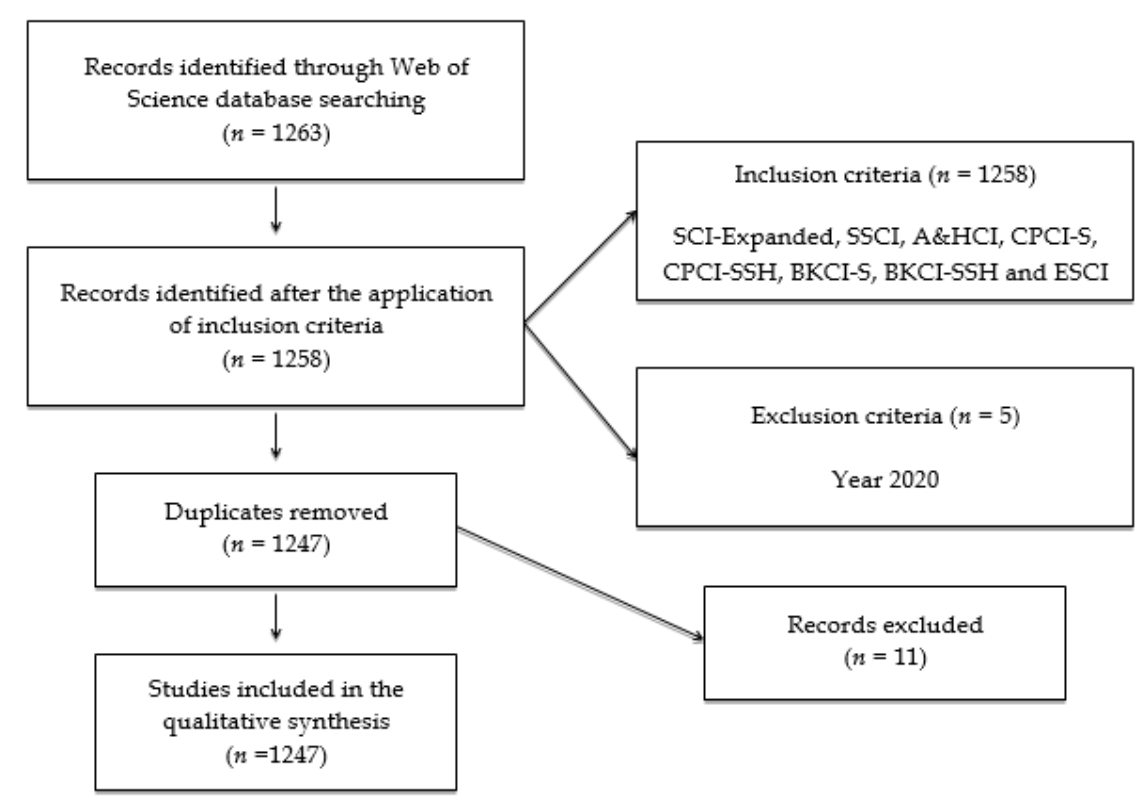

Figure 1. Flowchart according to the PRISMA Declaration. 
Various tools were used for data analysis. To identify the year, type of document, institution, authors, media, country, language, and most cited documents, the Analyze Results and Create Citation Report tools were used, both typical of the WoS platform. SciMAT was used to study the structural development and longitudinal dynamism of the scientific publications, following the recommendations of the experts [49]. This software allowed to perform the following actions in the thematic-level co-word analysis:

- Recognition: This consisted of analyzing the keywords of all of the reported scientific productions $(n=3826)$ and generating a map of co-occurrence through nodes. This gave rise to a standardized network of co-words. In this way, the most relevant keywords were obtained $(n=3783)$, and with a clustering algorithm, the themes were defined, as well as the concepts with the greatest attraction among them.

- Reproduction: This was produced with the development of a strategic diagram and a thematic network based on the principles of centrality and density. The graphic representation was configured as four sectors: (1) Higher-right = brings together motor and relevant issues; (2) upper-left $=$ consolidated but isolated topics; (3) lower-left $=$ issues in development or disappearance; and (4) lower-right: cross-cutting issues with little development.

- Determination: This was carried out through a study of the evolution of the nodes in time intervals. Four intervals (i.e., $\mathrm{I}_{1}=1995-2008, \mathrm{I}_{2}=2009-2013, \mathrm{I}_{3}=2014-2016$, and $\mathrm{I}_{4}=2017-2019$ ) were established to classify and to analyze the reported documents. However, for the authors, a single interval was defined (i.e., $\left.\mathrm{I}_{\mathrm{X}}=1995-2019\right)$ that covers all of the reported productions. The strength of association was determined by the volume of common keywords at the configured intervals.

- Performance: This was obtained through the connections found between the keywords and the other concepts of the node. For this, the unit of analysis that determines the unit of assessment, which contains the keywords established by the authors in the documents, the keywords established by WoS, and the keywords of the authors in different publications, was analyzed. Another indicator, namely, the frequency threshold, was used to determine the minimum frequency of the intervals, with $n=3$ for the first and third intervals and $n=4$ for the second and fourth intervals. The type of network allowed to develop a network of co-occurrence of keywords and authors (co-words-co-authors). The coincidence union value allowed to articulate the established intervals (four intervals for the keywords and one for the years of production of the authors). The normalization measure determined the binding threshold, revealing the minimum connection of the occurrence (keywords $=\mathrm{I}_{1} \geq 2 ; \mathrm{I}_{2} \geq 2 ; \mathrm{I}_{3} \geq 2 ; \mathrm{I}_{4} \geq 2$; authors $=\mathrm{I}_{\mathrm{X}} \geq 3$ ). In order to normalize the connections, the equivalence index eij $=c i j 2 / R o o t(c i-c j)$ was made. The clustering algorithm, through simple centers, was used to make the map of topics and related subnets. The evolutionary measure, through the Jaccard index, served to determine the measure of similarity that developed the evolution map and the transition map through the inclusion rate (Table 2).

Table 2. Production indicators and inclusion criteria at SciMAT.

\begin{tabular}{cc}
\hline Configuration & Values \\
\hline Analysis unit & Keywords authors, keywords WoS \\
Frequency threshold & Keywords: $\mathrm{I}_{1}=(3), \mathrm{I}_{2}=(4), \mathrm{I}_{3}=(3), \mathrm{I}_{4}=(4)$ \\
Network type & Authors: $\mathrm{I}_{\mathrm{X}}=(3)$ \\
Co-occurrence & \\
Co-occurrence union value threshold & Keywords: $\mathrm{I}_{1}=(2), \mathrm{I}_{2}=(2), \mathrm{I}_{3}=(2), \mathrm{I}_{4}=(2)$ \\
Normalization measure & Authors: $\mathrm{I}_{\mathrm{X}}=(3)$ \\
Clustering algorithm & Equivalence index \\
Evolutionary measure & Maximum size: $9 ;$ minimum size: 3 \\
Overlapping measure & Jaccard index \\
\hline
\end{tabular}

Note: $\mathrm{I}_{1}$ : The interval from 1995 to $2008 ; \mathrm{I}_{2}$ : the interval from 2009 to $2013 ; \mathrm{I}_{3}$ : the interval from 2014 to 2016; $\mathrm{I}_{4}$ : the interval from 2017 to 2019; $\mathrm{I}_{\mathrm{X}}$ : 1995-2019. WoS, Web of Science. 


\section{Results}

\subsection{Performance and Scientific Production}

Of the 1263 documents analyzed to elaborate the temporal evolution of the development of the subject, the works produced from 1995 onward were represented (Figure 2), given that there were no adequate records of them in WoS. From this date, scientific production was irregular, with little incidence until 2009, prior to which the presentation of academic results was scarce. From 2010 onward, production has increased, although it is still irregular, as there was a considerable decrease in 2015 and a rebound from 2018 onward.

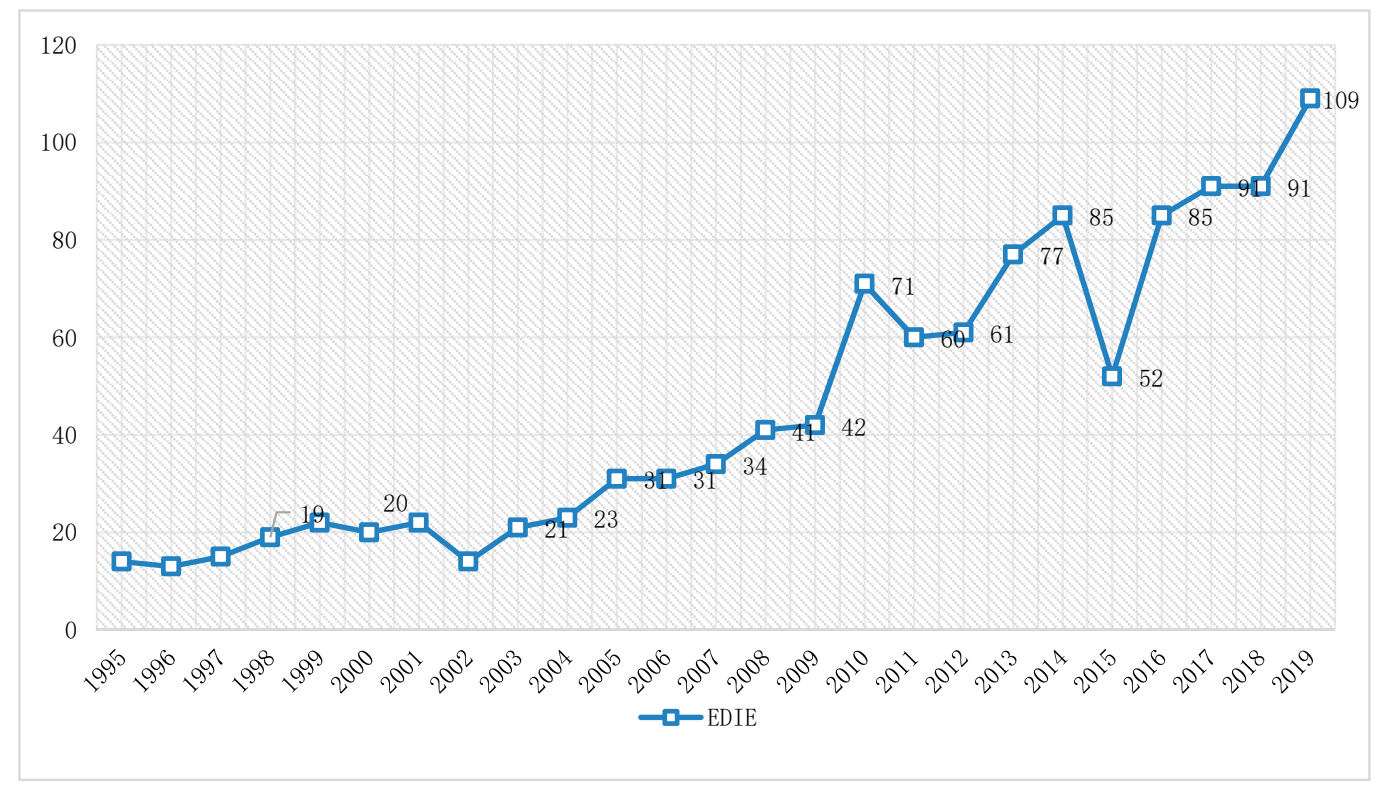

Figure 2. Evolution of the scientific production of diet in education in the Web of Science (WoS). EDIE: education and diet.

The language par excellence in this type of production is English, which is used well above the other languages (Table 3).

Table 3. Scientific language used in EDIE.

\begin{tabular}{cc}
\hline Language & $\boldsymbol{n}$ \\
\hline English & 1154 \\
Spanish & 49 \\
German & 15 \\
Portuguese & 13 \\
\hline
\end{tabular}

The primary area where this subject is represented is Nutrition Dietetics, followed by Public Environmental Occupational Health, being the fields where education is most relevant in relation to diet (Table 4).

Table 4. Research areas.

\begin{tabular}{cc}
\hline Research Area & $\boldsymbol{n}$ \\
\hline Nutrition Dietetics & 375 \\
Public Environmental Occupational Health & 251 \\
Education Educational Research & 141 \\
General Internal Medicine & 112 \\
Endocrinology Metabolism & 109 \\
\hline
\end{tabular}


With respect to the type of document that scientists use to present their results, this would be articles, being favored distinctly more than the rest of the production types (Table 5).

Table 5. Document types.

\begin{tabular}{cc}
\hline Document Types & $\boldsymbol{n}$ \\
\hline Article & 1036 \\
Proceedings paper & 87 \\
Meeting abstract & 83 \\
Review & 58 \\
Editorial material & 22 \\
\hline
\end{tabular}

At the institutional level, there are three institutions that present an even production on the subject, namely, the Pennsylvania Commonwealth System of Higher Education (PCSHE), the University of California System, and the University of London. The rest of the institutions shown in Table 6 offer a relevant production, with hardly a distinction from the first three.

Table 6. Institution.

\begin{tabular}{cc}
\hline Institution & $\boldsymbol{n}$ \\
\hline Pennsylvania Commonwealth System of Higher Education (PCSHE) & 30 \\
University of California System & 29 \\
University of London & 29 \\
University of North Carolina & 26 \\
United States Department of Agriculture (USDA) & 25 \\
Penn State University & 22 \\
National Institutes of Health (NIH USA) & 20 \\
University of Texas System & 20 \\
\hline
\end{tabular}

In reference to the most prolific authors, A.H. Lichtenstein and Y. Manios are the largest producers in EDIE, although their production is not much above the rest of the authors (Table 7).

Table 7. Authors.

\begin{tabular}{cl}
\hline Authors & $\boldsymbol{n}$ \\
\hline Lichtenstein, A.H. & 9 \\
Manios, Y. & 9 \\
Schaefer, E.J. & 8 \\
Kafatos, A. & 7 \\
Campbell, N.R.C. & 6 \\
Feldman, R.D. & 6 \\
Hamet, P. & 6 \\
Khan, N.A. & 6 \\
Larochelle, P. & 6 \\
Leiter, L.A. & 6 \\
Ogilvie, R.I. & 6 \\
Padwal, R. & 6 \\
Pylypchuk, G. & 6 \\
Schiffrin, E.L. & 6 \\
Touyz, R.M. & 6 \\
\hline
\end{tabular}

The two main sources where the EDIE theme is presented are the Journal of the American Dietetic Association and Public Health Nutrition. The rest of the sources, although to a lesser extent, show a relevant production on this subject (Table 8). 
Table 8. Source titles.

\begin{tabular}{cc}
\hline Source Titles & $\boldsymbol{n}$ \\
\hline Journal of the American Dietetic Association & 36 \\
Public Health Nutrition & 35 \\
Journal of Nutrition Education and Behavior & 26 \\
American Journal of Clinical Nutrition & 19 \\
Nutrients & 19 \\
BMC Public Health & 17 \\
FASEB Journal & 16 \\
Patient Education and Counseling & 15 \\
\hline
\end{tabular}

The country most interested in EDIE is the United States, which is far above the rest of the other countries (Table 9).

Table 9. Countries.

\begin{tabular}{cc}
\hline Country & $\boldsymbol{n}$ \\
\hline United States & 482 \\
England & 99 \\
Spain & 69 \\
Australia & 64 \\
Canada & 63 \\
China & 38 \\
Italy & 37 \\
Japan & 36 \\
Poland & 36 \\
Germany & 35 \\
\hline
\end{tabular}

The most frequently cited publication in the field of EDIE is undoubtedly that of Pi-Sunyer (1998). The rest also present high levels of citations, which indicates that such research is of relevance to the scientific community (Table 10).

Table 10. Most cited articles.

\begin{tabular}{|c|c|}
\hline Reference & Citations \\
\hline $\begin{array}{l}\text { Pi-Sunyer, F.X. NHLBI Obesity Education Initiative Expert Panel on the } \\
\text { identification, evaluation, and treatment of overweight and obesity in } \\
\text { adults-The evidence report. Obesity Research 1998, 6, 51-209. }\end{array}$ & 3802 \\
\hline $\begin{array}{c}\text { Norris, S.L.; Lau, J.; Smith, S.J.; Schmid, C.H.; Engelgau, M.M. } \\
\text { Self-management education for adults with type } 2 \text { diabetes-A } \\
\text { meta-analysis of the effect on glycemic control. Diabetes Care 2002, 25, } \\
\text { 1159-1171. https://doi.org/10.2337/diacare.25.7.1159 }\end{array}$ & 941 \\
\hline $\begin{array}{l}\text { Whelton, P.K.; He, J.; Appel, L.J.; Cutler, J.A.; Havas, S.; Kotchen, T.A.; } \\
\text { Roccella, E.J.; Stout, R.; Vallbona, C.; Winston, M.C.; Karimbakas, J. } \\
\text { Primary prevention of hypertension-Clinical and public health } \\
\text { advisory from the National High Blood Pressure Education Program. } \\
\text { JAMA- Journal of the American Medical Association 2002, 288, } \\
\text { 1882-1888. https://doi.org/10.1001/jama.288.15.1882 }\end{array}$ & 849 \\
\hline $\begin{array}{l}\text { Muers, G.L.; Miller, W.G.; Coresh, J.; Fleming, J.; Greenberg, N.; Greene, } \\
\text { T.; Hostetter, T.; Levey, A.S.; Panteghini, M.; Welch, M.; Eckfeldt, J.H. } \\
\text { Recommendations for improving serum creatinine measurement: A } \\
\text { report from the laboratory working group of the National Kidney } \\
\text { Disease Education Program. Clinical Chemistry 2006, 52, 5-18. } \\
\text { https://doi.org/10.1373/clinchem.2005.0525144 }\end{array}$ & 793 \\
\hline $\begin{array}{l}\text { Pi-Sunyer, F.X. NHLBI Obesity Education Initiative Expert Panel on the } \\
\text { identification, evaluation, and treatment of overweight and obesity in } \\
\text { adults - The evidence report. Obesity Research 1998, 6, 51-209. }\end{array}$ & 3802 \\
\hline
\end{tabular}




\subsection{Structural and Thematic Development}

The evolution of the keywords offers information about the words that appear or are included in a certain interval and also shows the coincidence between the established dates. In this case, the four intervals generated present a base regarding the subject matter, given that there is a coincidence of between $30 \%$ and $40 \%$ in their keywords. The development of the same in the established intervals remains stable, as far as quantity is concerned (Figure 3).

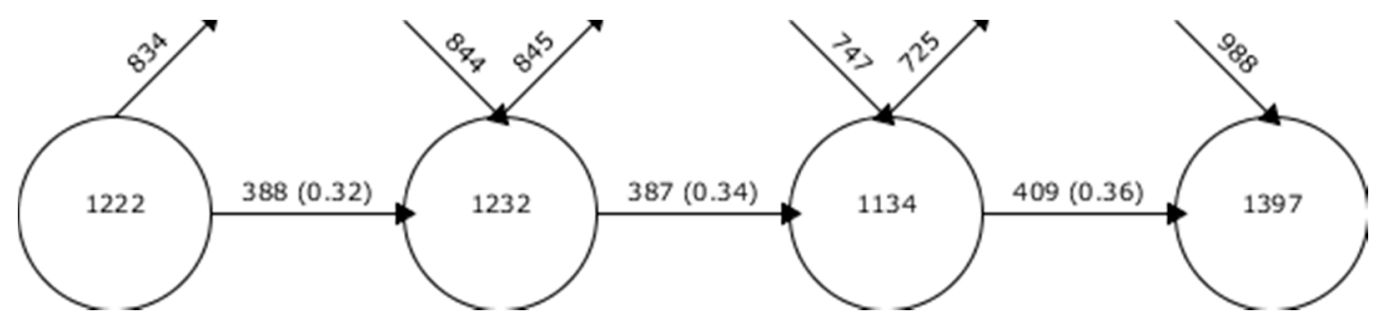

Figure 3. Continuity of keywords between contiguous intervals.

The academic performance in each of the intervals shows the topics with various bibliometric indicators, presenting, in this case, the h-index, the g-index, the hg-index, and the q2-index, thus offering information on the most relevant topics in each of the intervals marked. As presented in Table 11, in the first interval (1995-2008), the "diet" theme stands out from the rest, with some indicators that duplicate other intervals. In this case, "coronary-heart-disease" and "children" follow at a great distance. In the second interval (2009-2013), the most relevant theme is "physical-activity," followed, with half of the bibliometric values, by "mellitus." In the third interval (2014-2016), "childhood" stands out, followed by "nutrition." In this interval, the distance between both themes is not very wide. In the last interval (2017-2019), the theme "fruit" is the most relevant, which is followed at a short distance by "children," "behavior," and "Mediterranean diet."

Table 11. Thematic performance.

\begin{tabular}{ccccccc}
\hline \multicolumn{7}{c}{ Interval 1995-2008 } \\
\hline Denomination & Works & h-Index & g-Index & hg-Index & q2-Index & Citations \\
\hline Lifestyle-interventions & 9 & 8 & 9 & 8.49 & 23.49 & 464 \\
Coronary-heart-disease & 28 & 17 & 28 & 21.82 & 30.02 & 2038 \\
Children & 28 & 19 & 28 & 23.07 & 32.03 & 1192 \\
Patient-education & 20 & 13 & 20 & 16.12 & 18.38 & 1463 \\
Social-class & 22 & 16 & 22 & 18.76 & 26.53 & 823 \\
Program & 17 & 11 & 17 & 13.67 & 18.17 & 358 \\
Men & 13 & 11 & 13 & 11.96 & 21.24 & 1396 \\
Diet & 60 & 29 & 56 & 40.3 & 35.72 & 3166 \\
Prevention & 15 & 11 & 15 & 12.85 & 19.34 & 605 \\
Women & 13 & 10 & 13 & 11.4 & 22.8 & 498 \\
Nutrition-education & 15 & 12 & 15 & 13.42 & 16.61 & 291 \\
Mortality & 13 & 12 & 13 & 12.49 & 20.2 & 1296 \\
Obesity & 11 & 10 & 11 & 10.49 & 21.21 & 636 \\
Readmission & 6 & 6 & 6 & 6 & 15.1 & 222 \\
Fitness & 3 & 3 & 3 & 3 & 14.18 & 253 \\
Efficacy & 3 & 3 & 3 & 3 & 9.49 & 87 \\
Lipids & 4 & 4 & 4 & 4 & 12.81 & 107 \\
Nurses & 4 & 4 & 4 & 4 & 11.14 & 99 \\
\hline
\end{tabular}


Table 11. Cont.

\begin{tabular}{|c|c|c|c|c|c|c|}
\hline \multicolumn{7}{|c|}{ Interval 2009-2013 } \\
\hline Denomination & Works & h-Index & g-Index & hg-Index & q2-Index & Citations \\
\hline Childhood-obesity & 15 & 8 & 15 & 10.95 & 20.78 & 347 \\
\hline Mellitus & 29 & 12 & 21 & 15.87 & 16.97 & 476 \\
\hline Blood-pressure & 12 & 8 & 12 & 9.8 & 12.33 & 328 \\
\hline Physical-activity & 60 & 17 & 25 & 20.62 & 22.58 & 806 \\
\hline Consumption & 23 & 12 & 22 & 16.25 & 19.29 & 655 \\
\hline Risk & 37 & 15 & 22 & 18.17 & 18.17 & 518 \\
\hline Care & 14 & 10 & 14 & 11.83 & 15.17 & 250 \\
\hline Adolescents & 22 & 14 & 21 & 17.15 & 21.49 & 566 \\
\hline Program & 13 & 8 & 12 & 9.8 & 10.95 & 208 \\
\hline Health-education & 11 & 6 & 10 & 7.75 & 12.25 & 131 \\
\hline Self-efficacy & 5 & 4 & 5 & 4.47 & 6.32 & 77 \\
\hline Nutrition-knowledge & 3 & 3 & 3 & 3 & 6 & 67 \\
\hline Questionnaire & 4 & 3 & 4 & 3.46 & 4.58 & 33 \\
\hline \multicolumn{7}{|c|}{ Interval 2014-2016 } \\
\hline Denomination & Works & h-Index & g-Index & hg-Index & q2-Index & Citations \\
\hline Childhood & 40 & 11 & 19 & 14.46 & 16.25 & 440 \\
\hline Self-management & 13 & 5 & 11 & 7.42 & 12.45 & 137 \\
\hline Fruit & 18 & 8 & 11 & 9.38 & 9.8 & 150 \\
\hline Cardiovascular-disease & 11 & 4 & 10 & 6.32 & 4.47 & 114 \\
\hline Socioeconomic-status & 13 & 7 & 12 & 9.17 & 11.22 & 149 \\
\hline Nutrition & 31 & 8 & 13 & 10.2 & 11.31 & 207 \\
\hline Diet & 29 & 10 & 17 & 13.04 & 14.83 & 341 \\
\hline Impact & 21 & 9 & 15 & 11.62 & 13.08 & 258 \\
\hline Patient-education & 7 & 5 & 7 & 5.92 & 8.06 & 92 \\
\hline Health-education & 7 & 4 & 5 & 4.47 & 5.29 & 30 \\
\hline \multicolumn{7}{|c|}{ Interval 2017-2019 } \\
\hline Denomination & Works & h-Index & g-Index & hg-Index & q2-Index & Citations \\
\hline Fruit & 46 & 6 & 15 & 9.49 & 10.95 & 251 \\
\hline Mediterranean-diet & 32 & 6 & 14 & 9.17 & 9.49 & 227 \\
\hline Children & 35 & 4 & 6 & 4.9 & 6.32 & 57 \\
\hline Behavior & 34 & 4 & 6 & 4.9 & 5.29 & 53 \\
\hline United-States & 10 & 3 & 6 & 4.24 & 5.74 & 38 \\
\hline Diet-quality & 9 & 2 & 3 & 2.45 & 3.16 & 13 \\
\hline Nutrition-education & 19 & 5 & 9 & 6.71 & 7.07 & 97 \\
\hline Type-2-Diabetes & 8 & 2 & 5 & 3.16 & 8.37 & 41 \\
\hline Education & 25 & 4 & 11 & 6.63 & 8.72 & 122 \\
\hline Health & 16 & 3 & 6 & 4.24 & 5.74 & 43 \\
\hline Meta-analysis & 11 & 2 & 4 & 2.83 & 4 & 18 \\
\hline Sedentary-behavior & 5 & 2 & 3 & 2.45 & 3.16 & 9 \\
\hline Care & 6 & 2 & 2 & 2 & 2.45 & 7 \\
\hline Population & 5 & 2 & 3 & 2.45 & 6.46 & 10 \\
\hline Attitudes & 4 & 1 & 1 & 1 & 1.41 & 4 \\
\hline Hemodialysis & 4 & 2 & 2 & 2 & 3.16 & 9 \\
\hline Quality & 3 & 1 & 1 & 1 & 1 & 1 \\
\hline
\end{tabular}

The diagrams of the established intervals provide information on the relevance of each of the themes, through a process of grouping, bearing in mind Callon's indicators, which analyze the degree of interaction of a network with respect to the other networks from two perspectives: centrality, which measures the strength of external links with other topics, being the measure of the importance of a topic in the development of a certain field of research; and density, which analyzes the internal strength of the network, identifying the internal links between all key words grouped around a specific 
topic, thus offering the degree of development of the field of study analyzed. The analysis of the four established diagrams shows that there is no common driving theme in any of the intervals, except in the last two, where "fruit" stands out as relevant within the scientific field. In the first interval, "patient education," "children," "coronary-heart-disease," "men," and "social-class" emerge as the driving theme; in the second interval, "mellitus," "childhood obesity," "physical-activity," and "consumption"; in the third, "childhood" and "fruit"; and in the fourth, "fruit," "Mediterranean-diet," "behavior," "United States," and "children." Focusing the analysis on the last interval, because it is the one that marks the new trends in research on the established field of study, the themes "attitudes," "population, "sedentary behavior," "quality," and "care" may be the new trends in research in this field, or may end up disappearing, given that their location in the diagram places them as unknown themes (Figure 4).

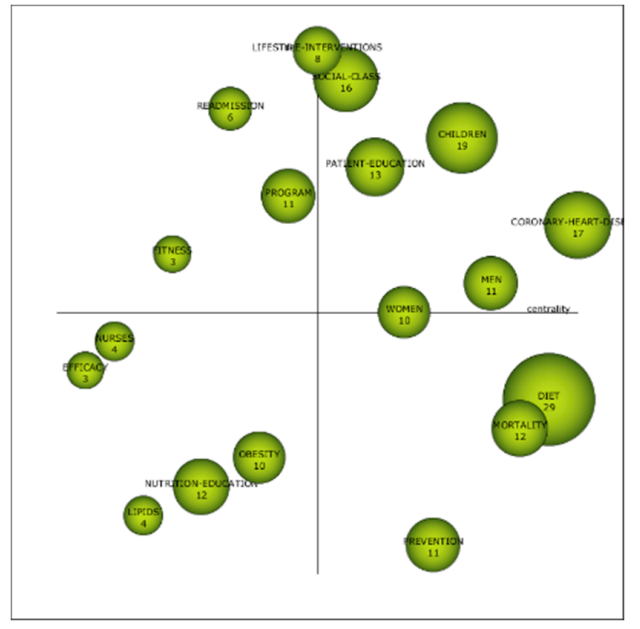

(a)

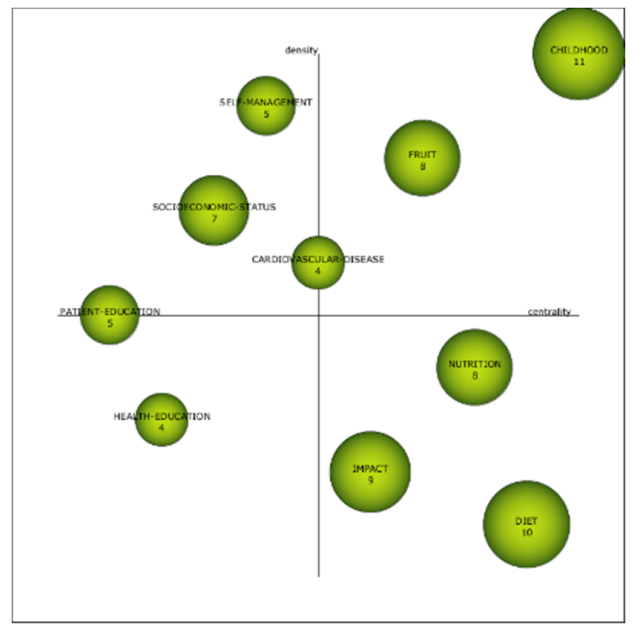

(c)

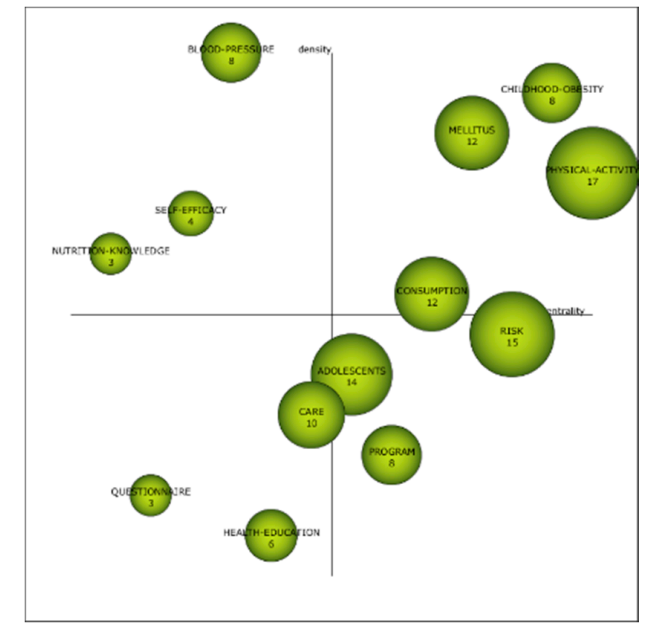

(b)

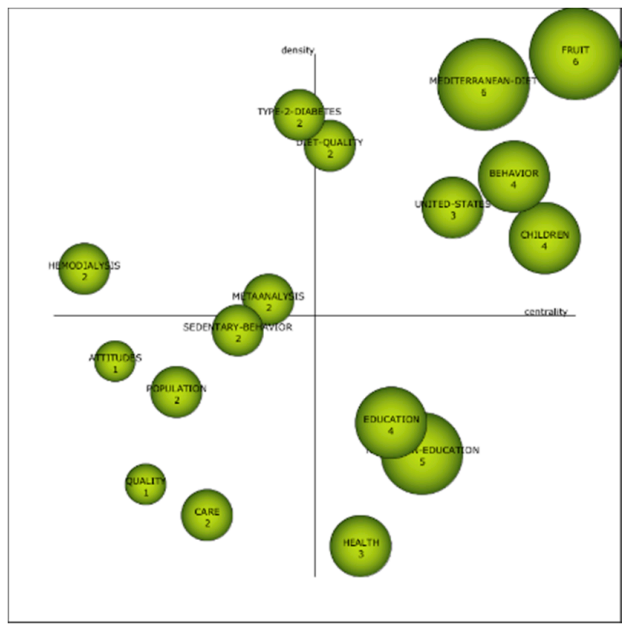

(d)

Figure 4. EDIE's strategic diagram by h-index. Note: (a) Interval 1995-2008; (b) interval 2009-2013; (c) interval 2014-2016; (d) interval 2017-2019.

\subsection{Thematic Evolution of the Terms}

Thematic evolution represents the strength of the relationship established between the themes of the various intervals generated, bearing in mind the Jaccard index. Evolution occurs if a theme of a certain interval shares keywords with the previous or contiguous intervals. The more keywords an interval has in relation to the themes of consecutive intervals, the more solid will be their evolution. The two types of connections that can occur are a continuous line, where its connection is thematic, 
and a discontinuous line, where its connection is through keywords. The thickness of the lines shows the strength of the relationship between the themes.

Based on the results obtained in Figure 5, it can be determined that there is a conceptual gap in EDIE, given that there is not a theme that is repeated in the four intervals, although there is an evolution of various themes over time, where there is a connection but the field of research varies, as can be seen in "diet," "patient-education," or "nutrition-education." Thematic evolution in this field of research begins to be established in the third and fourth intervals, where the "fruit" theme stands out with strength and continuity over time. It should also be pointed out that, between the first and second intervals and the second and third intervals, the connections are mainly thematic, something that does not occur between the third and fourth intervals, where the connections are mainly of key words. Furthermore, in general, in the first and second intervals, the themes are focused on aspects more related to diseases, while in the second and third intervals they are oriented toward food, which marks a before and after in this field of research.

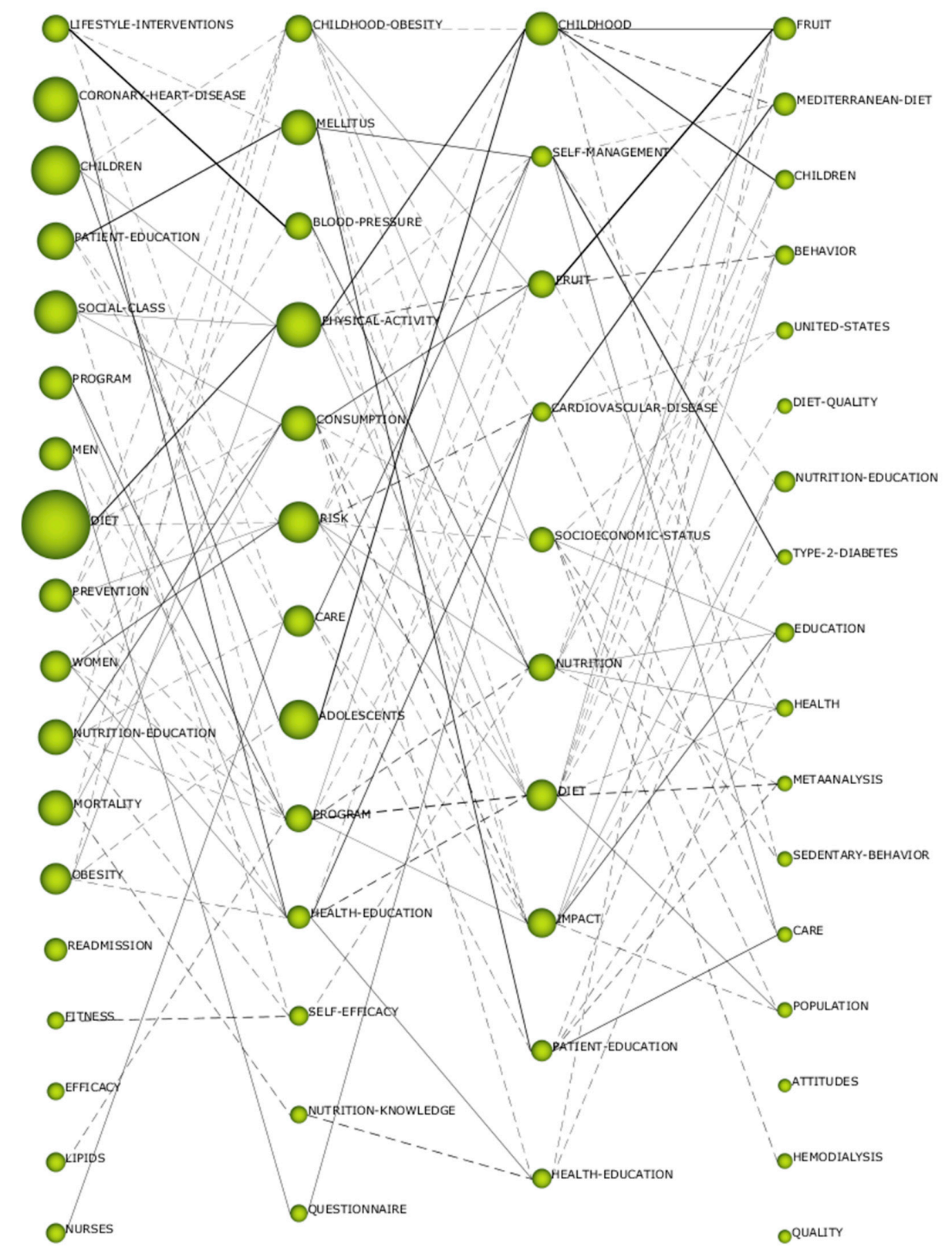

Figure 5. Thematic evolution by h-index. 


\subsection{Authors with a Higher Relevance Index}

Bearing in mind the results offered in Figure 6, it can be determined that there are relevant authors in EDIE, such as Khan, Mahon, or Leiter, or even unknown authors, who may become relevant or who may disappear in the coming years, such as Kafatos, Schaefer, or Carey.

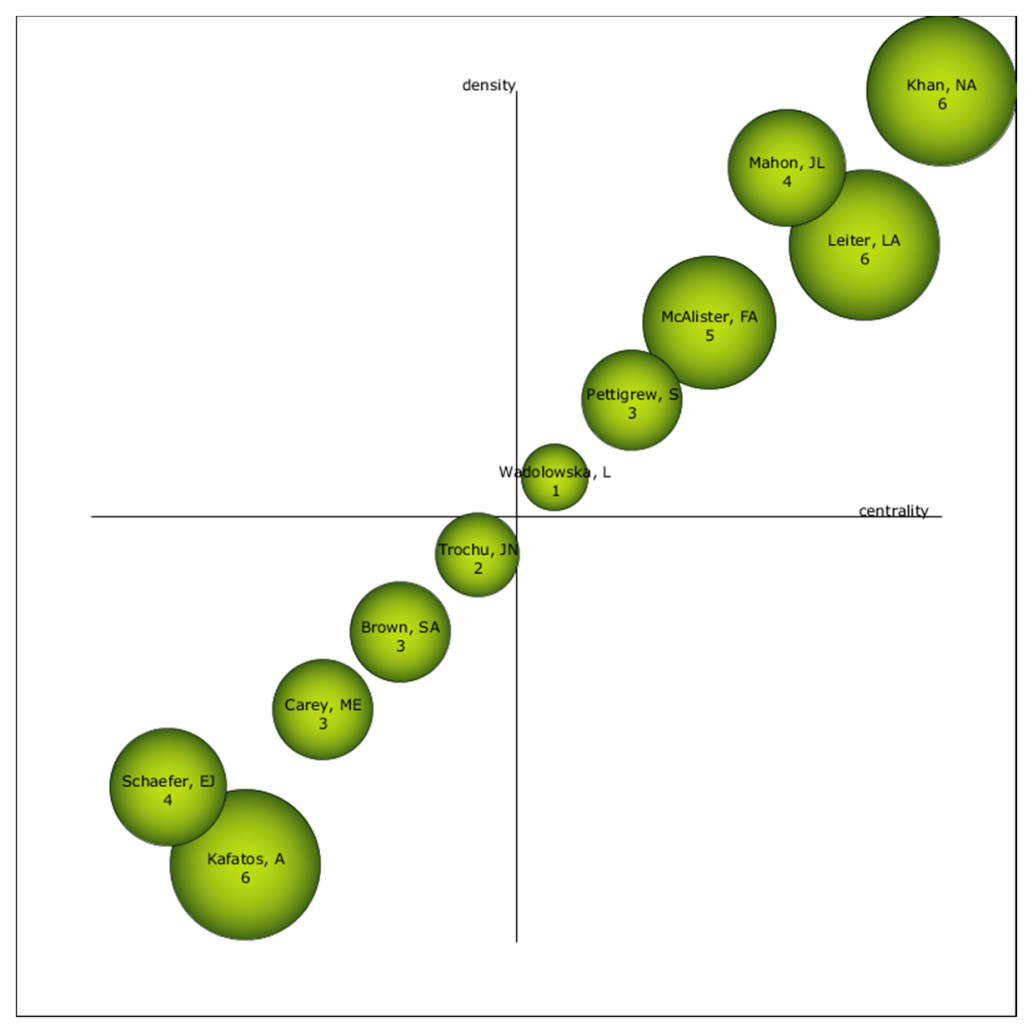

Figure 6. Strategic authoring diagram.

\section{Discussion and Conclusions}

Food is one of the most influential factors in people's health [1,2,5]. Experts recommend following a correct diet by adhering to dietary guidelines established by professionals [27]. In today's society, nutrition and dietetics are assuming an important value [32]. In addition to a sedentary lifestyle, obesity is affecting a large part of the population because they do not follow the appropriate nutritional recommendations for a proper diet $[3,4]$. As a consequence of this worrying situation, educational centers are carrying out initiatives and training programs to encourage the promotion of dietary education with the aim of improving students' knowledge $[6,7,9-11]$ and to encourage an active and healthy life in order to reduce the possibility of suffering from certain diseases resulting from a poor $\operatorname{diet}[17-19]$.

Unlike other studies related to the subject [36], this paper investigated the dynamic and structural development of the concepts "diet" and "education" in order to reveal new findings on the state of the art, using a novel technique, namely, analysis of bibliometric indicators. The results obtained highlight that the previously established objectives in this study were achieved.

As for the scientific production reporting on "diet" and "education," the results reveal that it experienced a turning point in 2009; prior to 2009, scientific documents dealing with both of these subjects were scarce and irregular, while from 2009 onward, the production grew, albeit irregularly, since in the years 2011-2012 and 2015, the production decreased.

The most common medium and language used by the scientific community to present their work is papers and English, respectively. The latter is related to the great interest that the United States has in this field of production. Within the area of research, Nutrition Dietetics, Public Environmental 
Occupational Health, the Journal of American Dietetic Association, Public Health Nutrition, and the Journal of Nutrition Education and Behavior are the most prominent. In terms of higher education, PCSHE, the University of California System, and the University of London are the most productive institutions regarding publications on "diet" and "education," while the most prolific authors on the subject are Lichtenstein, Manios, and Schaefer, not coinciding with the most cited authors, given that Pi-Sunyer (1998) is the most cited author in this field of knowledge, with a total of 3802 citations.

The evolution of "diet" and "education" throughout scientific production maintains a consolidated research base, given that there is a high percentage of coincidence in the key words of the intervals established for this study, but this fact is not reflected in the topics dealt with in each of them, seeing as very few are repeated between the intervals. It can also be observed that scientific production has a before and after in 2014, given that in the intervals prior to this date, the most common key words refer to medical- and disease-related aspects, while from 2014, the themes are more focused on prevention and the type of diet.

In all of the intervals analyzed, there is no theme that is based on time as a driving force; on the contrary, there is a great variety between the established dates, which marks new fields and new visions for researchers when studying "diet" and "education." It is in the last two intervals, since 2014, where a driving theme is glimpsed, which marks the trends of the investigations at that moment and not in the very near future as is the case for "fruit," with studies focusing on diet, obesity, young people, and feeding in schools.

When considering the near future in this field of research, we must bear in mind the themes "attitudes," "sedentary-behavior," "population," "quality," and "care," which, given their position in the 2017-2019 interval, may be the new trends and, therefore, will become the most relevant themes for the scientific community.

It can be concluded that the subjects of "diet" and "education" have been analyzed by the scientific community for more than 20 years. However, it is only in the last 10 years that these subjects have reached more relevance, focusing on aspects more related to disease prevention, primarily in terms of the type of feeding, with emphasis on fruit, which appears to be the main focus of investigators in this field of knowledge.

The aim of this research was to offer researchers new trends in the near future regarding the most relevant and interesting topics for the scientific community, as well as to highlight the aspects on which research has been based in recent times to provide a basis on which to start, develop, or guide their studies.

As a theoretical implication, this study provides specific information on the term diet in the educational field. That is, it analyzes the studies that refer to the actions developed in the educational field to train students on diet. In addition, it analyzes the diet programs applied in the different educational centers. From this perspective, the authors related to this subject are able to obtain concise information on the most prolific and current lines of research in this field of study.

As a practical implication, this study is useful for the educational community involved in the teaching of this subject to understand the most current trends, both at a pedagogical and at a didactic level. In addition, it helps to identify the most current topics and the most relevant and appropriate theoretical aspects to train students to develop an adequate diet.

There are several limitations presented in this research. The first relates to the purification of the data presented in WoS, where repeated documents are presented or are not related to the subject matter of the study. The second is related to the establishment of the intervals, which, in this case, is a question of equity, given that the researchers sought at all times to maintain a similar number of documents in each of the intervals. Thirdly, the parameters marked in this study were established according to the researchers' own criteria, which sought to present the results in accordance with their size and relevance. Finally, another limitation of this study is found in the analysis of the h-index. Other experts in this type of research [50] consider that it is not an objective indicator to establish the relevance or impact of researchers. For this reason, the data presented here should be viewed with 
caution, given that the change in the parameters established in this research may lead to a variation in the number of and the connections in the subjects presented. As future lines of research, we propose to develop practical applications and pedagogical actions in the educational field focused on diet. A study can also be performed on other databases, such as SCOPUS or Google Scholar, as well as an analytical analysis of the literature using more advanced techniques, as other studies suggest [51].

Author Contributions: Conceptualization, J.A.L.N., M.R.N.-P., and J.L.-B.; methodology, J.L.-B.; software, A.-J.M.-G.; formal analysis, A.-J.M.-G.; investigation, J.A.L.N., M.R.N.-P., J.L.-B., A.-J.M.-G., and F-.J.H-.L.; data curation, J.L.-B. and A.-J.M.-G.; writing-original draft preparation, J.A.L.N., M.R.N.-P., J.L.-B., A.-J.M.-G., and F.-J.H.-L.; writing-review and editing, J.A.L.N., M.R.N.-P., J.L.-B., A.-J.M.-G., and F.-J.H.-L.; visualization, J.A.L.N.; supervision, F.-J.H.-L. All authors read and agreed to the published version of the manuscript.

Funding: This study was financed by the "Study and analysis of technological resources and innovation in teacher training in the field of Higher Education and its applicability to the development of the Santander Region (Colombia)," in the Framework Cooperation Agreement for the strengthening of research and education, signed between the Corporación Escuela Tecnológica del Oriente, the Secretariat of Education of Santander, and the AreA HUM/672 Research Group of the University of Granada. Code: ISPRS-2017-7202. Period: 2017 to 2021.

Acknowledgments: The authors acknowledge the researchers of the research group AREA (HUM-672), which belongs to the Ministry of Education and Science of the Junta de Andalucía and is registered in the Department of Didactics and School Organization of the Faculty of Education Sciences of the University of Granada.

Conflicts of Interest: The authors declare no conflict of interest.

\section{References}

1. Vahedian-Shahroodi, M.; Tehrani, H.; Robat-Sarpooshi, D.; GHolian-Aval, M.; Jafari, A.; Alizadeh-Siuki, H. The impact of health education on nutritional behaviors in female students: An application of health belief model. Int. J. Health Promot. Educ. 2019, 1-13. [CrossRef]

2. Thorpe, M.G.; Milte, C.M.; Crawford, D.; McNaughton, S.A. Education and lifestyle predict change in dietary patterns and diet quality of adults 55 years and over. Nutr. J. 2019, 18, 67. [CrossRef]

3. Trigueros, R.; Mínguez, L.A.; González-Bernal, J.J.; Jahouh, M.; Soto-Camara, R.; Aguilar-Parra, J.M. Influence of Teaching Style on Physical Education Adolescents' Motivation and Health-Related Lifestyle. Nutrients 2019, 11, 2594. [CrossRef]

4. Karamat, F.; Tahir, T.; Hanif, M.; Gul, Z. Analysis of oral hygiene education in obese children in local population of Pakistan. Indo Am. J. Pharm. Sci. 2018, 5, 4312-4316.

5. Aggarwal, M.; Devries, S.; Freeman, A.M.; Ostfeld, R.; Gaggin, H.; Taub, P.; Rzeszut, A.K.; Allen, K.; Conti, R.C. The deficit of nutrition education of physicians. Am. J. Med. 2018, 131, 339-345. [CrossRef]

6. Gvozdanović, Z.; Farčić, N.; Placento, H.; Lovrić, R.; Dujmić, Ž.; Jurić, A.; Miškić, B.; Prlić, N. Diet Education as a Success Factor of Glycemia Regulation in Diabetes Patients: A Prospective Study. Int. J. Environ. Res. Public Health 2019, 16, 4003. [CrossRef] [PubMed]

7. Prescott, M.P.; Burg, X.; Metcalfe, J.J.; Lipka, A.E.; Herritt, C.; Cunningham-Sabo, L. Healthy planet, healthy youth: A food systems education and promotion intervention to improve adolescent diet quality and reduce food waste. Nutrients 2019, 11, 1869. [CrossRef]

8. Santaló, M.I.; Gibbons, S.; Naylor, P.J. Using Food Models to Enhance Sugar Literacy among Older Adolescents: Evaluation of a Brief Experiential Nutrition Education Intervention. Nutrients 2019, 11, 1763. [CrossRef] [PubMed]

9. Zeng, D.; Fang, Z.L.; Qin, L.; Yu, A.Q.; Ren, Y.B.; Xue, B.Y.; Zhou, X.; Gao, Z.Y.; Ding, M.; An, N.; et al. Evaluation for the effects of nutritional education on Chinese elite male young soccer players: The application of adjusted dietary balance index (DBI). J. Exerc. Sci. Fit. 2020, 18, 1-6. [CrossRef] [PubMed]

10. Belski, R.; Donaldson, A.; Staley, K.; Skiadopoulos, A.; Randle, E.; O’Halloran, P.; Kappelides, P.; Teakel, S.; Stanley, S.; Nicholson, M. Brief education intervention increases nutrition knowledge and confidence of coaches of junior Australian football teams. Int. J. Sport Nutr. Exerc. Metab. 2018, 28, 259-265. [CrossRef] [PubMed]

11. Casagrande, K.; Zandonai, R.C.; de Matos, C.H.; Wachholz, L.B.; Mezadri, T.; Grillo, L.P. Evaluation of the effectiveness of food and nutritional education in the elderly. Rbne-Revista Brasileira De Obesidade Nutricao E Emagrecimiento 2018, 12, 591-597. 
12. Hemamalini, J.; Babitha, B. Development Of Nutritional Status By Nutrition Education For School Going Boys (13 To 15 Years) In Vijayawada And Chennai. Res. J. Pharm. Biol. Chem. Sci. 2018, 9, 1041-1048.

13. López-Belmonte, J.; Pozo-Sánchez, S.; Fuentes, A.; Fuentes, P.Á. Liderazgo de un grupo de trabajo saludable en una cooperativa educativa. Magis Revista Int. De Invest. En Educ. 2019, 12, 129-144. [CrossRef]

14. Crema, A.M.; Bispo, A.; Enomoto, C.; Brito, S.; Amaro, S.; Oller, T.; Alvarenga, M.L. Nutritional education and preparations for acceptance of assessment culinary containing fruit and vegetables for athletes teens. Rbne-Revista Brasileira De Nutricao Esportiva 2017, 11, 24-31.

15. Rodríguez, J.E.; Gigirey, A.; Ramos, A. Analysis of eating habits and physical activity in Galician students of primary education. Sport.-Sci. Tech. J. Sch. Sport Phys. Educ. Psychomot. 2018, 4, 508-526. [CrossRef]

16. Gerritsen, S.; Anderson, S.E.; Morton, S.M.; Wall, C.R. Pre-school nutrition-related behaviours at home and early childhood education services: Findings from the Growing Up in New Zealand longitudinal study. Public Health Nutr. 2018, 21, 1222-1231. [CrossRef]

17. De Oliveira, I.C.; Navarro, F. Characterization of nutritional status, physical activity and school supply between 9 and 10 years of public education of Coimbra-MG. Rbne-Revista Brasileira De Nutricao Esportiva 2017, 11, 327-338.

18. Gianfrancesco, C.; Johnson, M. Exploring the provision of diabetes nutrition education by practice nurses in primary care settings. J. Hum. Nutr. Diet. 2019. [CrossRef]

19. Aspry, K.E.; Van Horn, L.; Carson, J.A.S.; Wylie-Rosett, J.; Kushner, R.F.; Lichtenstein, A.H.; Devries, S.; Freeman, A.M.; Crawford, A.; Kris-Etherton, P. Medical nutrition education, training, and competencies to advance guideline-based diet counseling by physicians: A science advisory from the American Heart Association. Circulation 2018, 137, e821-e841. [CrossRef]

20. Black, M.; LaCroix, R.; Hoerster, K.; Chen, S.; Ritchey, K.; Souza, M.; Utech, A.; Thielke, S. Healthy Teaching Kitchen Programs: Experiential Nutrition Education Across Veterans Health Administration. Am. J. Public Health 2019, 109, 1718-1721. [CrossRef]

21. Chiu, C.J.; Kuo, S.E.; Lin, D.C. Technology-embedded health education on nutrition for middle-aged and older adults living in the community. Glob. Health Promot. 2019, 26, 80-87. [CrossRef] [PubMed]

22. Stotz, S.A.; Thompson, J.J.; Bhargava, V.; Scarrow, A.; Capitano, K.; Lee, J.S. A Supplemental Produce and eLearning Nutrition Education Program for Georgians Who Use Safety-Net Clinics for Their Health Care. J. Nutr. Educ. Behav. 2019, 51, 1099-1106. [CrossRef] [PubMed]

23. Gabrielli, S.; Dianti, M.; Maimone, R.; Betta, M.; Filippi, L.; Ghezzi, M.; Forti, S. Design of a mobile app for nutrition education (TreC-LifeStyle) and formative evaluation with families of overweight children. JMIR mHealth uHealth 2017, 5, e48. [CrossRef] [PubMed]

24. López-Belmonte, J.; Pozo-Sánchez, S.; Fuentes, A.; Romero-Rodríguez, J.M. Effectiveness of learning with flipped learning with augmented reality in school health education. J. Sport Health Res. 2020, 12, 64-79.

25. Kariya, C.; Bell, K.; Bellamy, C.; Lau, J.; Yee, K. Blenderized Tube Feeding: A Survey of Dietitians' Perspectives, Education, and Perceived Competence. Can. J. Diet. Pract. Res. 2019, 80, 190-194. [CrossRef]

26. Partida, S.; Marshall, A.; Henry, R.; Townsend, J.; Toy, A. Attitudes toward Nutrition and Dietary Habits and Effectiveness of Nutrition Education in Active Adolescents in a Private School Setting: A Pilot Study. Nutrients 2018, 10, 1260. [CrossRef]

27. Uemura, M.; Hayashi, F.; Ishioka, K.; Ihara, K.; Yasuda, K.; Okazaki, K.; Omata, J.; Suzutani, T.; Hirakawa, Y.; Chiang, C.; et al. Obesity and mental health improvement following nutritional education focusing on gut microbiota composition in Japanese women: A randomised controlled trial. Eur. J. Nutr. 2019, 58, 3291-3302. [CrossRef]

28. Myszkowska-Ryciak, J.; Harton, A. Eating Healthy, Growing Healthy: Outcome Evaluation of the Nutrition Education Program Optimizing the Nutritional Value of Preschool Menus, Poland. Nutrients 2019, 11, 2438. [CrossRef]

29. Gabiola, J.; Morales, D.; Quizon, O.; Cadiz, R.I.; Feliciano, K.; Ruiz, R.L.; Aguatis, C.J.; Mararac, T.; Rojina, J.; García, A.; et al. The Effective Ness of LIfestyle with Diet and Physical Activity Education ProGram Among Prehypertensives and Stage 1 HyperTENsives in an Urban Community Setting (ENLIGHTEN) Study. J. Community Health 2019, 1-10. [CrossRef]

30. Correa-Burrows, P.; Rodríguez, Y.; Blanco, E.; Gahagan, S.; Burrows, R. Snacking quality is associated with secondary school academic achievement and the intention to enroll in higher education: A cross-sectional study in adolescents from Santiago, Chile. Nutrients 2017, 9, 433. [CrossRef] 
31. Vaughn, A.E.; Bartlett, R.; Luecking, C.T.; Hennink-Kaminski, H.; Ward, D.S. Using a social marketing approach to develop Healthy Me, Healthy We: A nutrition and physical activity intervention in early care and education. Transl. Behav. Med. 2019, 9, 669-681. [CrossRef] [PubMed]

32. Kushwah, S.; Dhir, A.; Sagar, M. Understanding consumer resistance to the consumption of organic food. A study of ethical consumption, purchasing, and choice behaviour. Food Qual. Prefer. 2019, 77, 1-14. [CrossRef]

33. Kushwah, S.; Dhir, A.; Sagar, M.; Gupta, B. Determinants of organic food consumption. A systematic literature review on motives and barriers. Appetite 2019, 143, 104402. [CrossRef] [PubMed]

34. Kushwah, S.; Dhir, A.; Sagar, M. Ethical consumption intentions and choice behavior towards organic food. Moderation role of buying and environmental concerns. J. Clean. Prod. 2019, 236, 117519. [CrossRef]

35. Anghel, G.A.; Gorghiu, G.; Lavinia, C.; Gorghui, L.M. Education for healthy eating in the actual curricular context-A case study. J. Sci. Arts 2017, 4, 815-822.

36. Trescastro-López, S.; Trescastro-López, E.M.; Galiana-Sánchez, M.E. A bibliometric study of food and nutrition education programmes and interventions in schools in Spain. Revista Española De Nutrición Humana Y Dietética 2014, 18, 184-193. [CrossRef]

37. Moreno, A.J.; Romero, J.M.; Ramos, M.; Alonso, S. Bibliometric Analysis on Educational Inspection in the Web of Science Database. Iberoam. Sobre Calid. Efica. Camb. Educ. 2020, 18, 83-103. [CrossRef]

38. Rodríguez, A.M.; Fernández, M.A.; Moreno, A.J. Scientific evolution of language teaching in a university context (1900-2019). Textos Livre 2019, 12, 16-36. [CrossRef]

39. López-Belmonte, J.; Moreno-Guerrero, A.J.; López-Núñez, J.; Pozo-Sánchez, S. Analysis of the Productive, Structural, and Dynamic Development of Augmented Reality in Higher Education Research on the Web of Science. Appl. Sci. 2019, 9, 5306. [CrossRef]

40. Khanra, S.; Dhir, A.; Mäntymäki, M. Big data analytics and enterprises: A bibliometric synthesis of the literature. Enterp. Inf. Syst. 2020, 1-32. [CrossRef]

41. Bhatt, Y.; Ghuman, K.; Dhir, A. Sustainable manufacturing. Bibliometrics and content analysis. J. Clean. Prod. 2020, 260, 120988. [CrossRef]

42. López-Belmonte, J.; Segura-Robles, A.; Moreno-Guerrero, A.J.; Parra-González, E. Machine Learning and Big Data in the Impact Literature. A Bibliometric Review with Scientific Mapping in Web of Science. Symmetry 2020, 12, 495. [CrossRef]

43. Moreno-Guerrero, A.J.; Gómez-García, G.; López-Belmonte, J.; Rodríguez-Jiménez, C. Internet Addiction in the Web of Science Database: A Review of the Literature with Scientific Mapping. Int. J. Environ. Res. Public Health 2020, 17, 2753. [CrossRef] [PubMed]

44. Rodríguez-García, A.M.; López-Belmonte, J.; Agreda-Montoro, M.; Moreno-Guerrero, A.J. Productive, Structural and Dynamic Study of the Concept of Sustainability in the Educational Field. Sustainability 2019, 11, 5613. [CrossRef]

45. Martínez, M.A.; Cobo, M.J.; Herrera, M.; Herrera, E. Analyzing the scientific evolution of social work using science mapping. Res. Soc. Work Pract. 2015, 25, 257-277. [CrossRef]

46. Hirsch, J.E. An index to quantify an individual's scientific research output. Proc. Natl. Acad. Sci. USA 2005, 102, 16569-16572. [CrossRef]

47. Cobo, M.J.; López, A.G.; Herrera, E.; Herrera, F. Science mapping software tools: Review, analysis, and cooperative study among tools. J. Am. Soc. Inf. Sci. Technol. 2011, 62, 1382-1402. [CrossRef]

48. López-Robles, J.R.; Otegi-Olaso, J.R.; Porto, I.; Cobo, M.J. 30 years of intelligence models in management and business: A bibliometric review. Int. J. Inf. Manag. 2019, 48, 22-38. [CrossRef]

49. Montero-Díaz, J.; Cobo, M.J.; Gutiérrez-Salcedo, M.; Segado-Boj, F.; Herrera-Viedma, E. Mapeo científico de la Categoría «Comunicación» en WoS (1980-2013). Comunicar 2018, 26, 81-91. [CrossRef]

50. Waltman, L.; van Eck, N.J. The inconsistency of the h-index. J. Am. Soc. Inf. Sci. Technol. 2012, 63, 406-415. [CrossRef]

51. Waltman, L.; van Eck, N.J.; van Leeuwen, T.N.; Visser, M.S.; van Raan, A.F. Towards a new crown indicator: An empirical analysis. Scientometrics 2011, 87, 467-481. [CrossRef] [PubMed]

(C) 2020 by the authors. Licensee MDPI, Basel, Switzerland. This article is an open access article distributed under the terms and conditions of the Creative Commons Attribution (CC BY) license (http://creativecommons.org/licenses/by/4.0/). 